\title{
Noninvasive positive pressure ventilation in the acute care setting: where are we?
}

\author{
N. Ambrosino**\# and G. Vagheggini ${ }^{\#}$
}

ABSTRACT: Noninvasive positive pressure ventilation (NPPV) is a technique used to deliver mechanical ventilation that is increasingly utilised in acute and chronic conditions. The present review examines the evidence supporting the use of NPPV in acute respiratory failure (ARF) due to different conditions.

Strong evidence supports the use of NPPV for ARF to prevent endotracheal intubation (ETI), as well as to facilitate extubation in patients with acute exacerbations of chronic obstructive pulmonary disease and to avoid ETI in acute cardiogenic pulmonary oedema, and in immunocompromised patients. Weaker evidence supports the use of NPPV for patients with ARF due to asthma exacerbations, with post-operative or post-extubation ARF, pneumonia, acute lung injury, acute respiratory distress syndrome, or during bronchoscopy. NPPV should be applied under close clinical and physiological monitoring for signs of treatment failure and, in such cases, ETI should be promptly available. A trained team, careful patient selection and optimal choice of devices can optimise outcome of NPPV.

Noninvasive positive pressure ventilation is increasingly being used in the management of acute respiratory failure but caregivers must respect evidence-supported indications and avoid contraidincations. Additionally, the technique must be applied in the appropriate location by a trained team in order to avoid disappointing results.

KEYWORDS: Acute respiratory failure, chronic obstructive pulmonary disease, endotracheal intubation, mechanical ventilation, noninvasive ventilation

W hen the cause of acute respiratory failure (ARF) is reversible, medical treatment works to maximise lung function and reverse the precipitating cause, whereas the aim of ventilatory support is to "gain time" by unloading respiratory muscles, increasing ventilation and thus reducing dyspnoea and respiratory rate, and improving arterial oxygenation and, eventually, hypercapnia and related respiratory acidosis [1]. Most of the complications of invasive mechanical ventilation (table 1) are related to endotracheal intubation (ETI) or to the placement of a tracheostomy tube, to baro- or volutrauma and to the loss of airway defence mechanisms; some others may follow extubation or complicate long-term tracheostomy [2]. Noninvasive mechanical ventilation may avoid most of these complications, ensuring at the same time a similar degree of efficacy [3]. Ventilationacquired pneumonia (VAP) and other nosocomial infections are reduced by noninvasive ventilation by preserving airway defence mechanisms, owing to the lower requirement for invasive monitoring $[4,5]$. This modality enhances patient's comfort, allowing for eating, drinking, cough and communication, avoiding or reducing the need for sedation without an increase in cost and nurse workload compared with invasive mechanical ventilation [6]. In addition, chest physiotherapy can be sufficiently applied. Many devices have been used in the past to deliver noninvasive mechanical ventilation: negative-pressure ventilators, iron lungs, pneumobelts and rocking beds, but in recent years there has been a prevalent, if not exclusive, use of noninvasive positive pressure ventilation (NPPV) [7].

Although continuous positive airway pressure (CPAP) is not considered as a form of ventilation since no inspiratory aid is applied, according to the International Consensus Conference 2001 (Paris, France) [8], NPPV is defined as any form of ventilatory support applied without ETI, and is considered to include: CPAP, with or without

\section{AFFILIATIONS}

*Pulmonary and Respiratory Intensive Care Unit, Cardio-Thoracic Dept, University Hospital Pisa, Pisa, and ${ }^{\#}$ Weaning and Pulmonary Rehabilitation Unit, Auxilium Vitae, Volterra, Italy.

\section{CORRESPONDENCE}

N. Ambrosino

U.0. Pneumologia

Dipartimento Cardio-Toracico

Azienda Ospedaliero-Universitaria Pisana

Via Paradisa 2

Cisanello

56124 Pisa

Italy

Fax: 39050996779

E-mail: n.ambrosino@

ao-pisa.toscana.it

Received:

October 312007

Accepted after revision:

December 272007

STATEMENT OF INTEREST

A statement of interest for

N. Ambrosino can be found at www.erj.ersjournals.com/misc/ statements.shtml 


\begin{tabular}{l} 
TABLE 1 Complications of invasive mechanical ventilation \\
Related to tube insertion \\
Aspiration of gastric contents \\
Trauma of teeth, pharynx, oesophagus, larynx, trachea \\
Sinusitis (nasotracheal intubation) \\
Need for sedation \\
Related to mechanical ventilation \\
Arrhythmias and hypotension \\
Barotrauma \\
Related to tracheostomy \\
Haemorrhage \\
Trauma of trachea and oesophagus \\
False lumen intubation \\
Stomal infections and mediastinitis \\
Tracheomalacia, tracheal stenoses and granulation tissue formation \\
Tracheo-oesophageal or tracheoarterial fistulas \\
Caused by loss of airway defence mechanisms \\
Airway colonisation with Gram-negative bacteria \\
Pneumonia \\
Occurring after removal of the endotracheal tube \\
Hoarseness, sore throat, cough and sputum \\
Haemoptysis \\
Vocal cord dysfunction and laryngeal swelling \\
\hline
\end{tabular}

inspiratory pressure support; volume- and pressure-cycled systems; proportional assist ventilation (PAV); and the use of helium-oxygen (heliox) gas mixtures.

NPPV is one of the most important developments in pulmonology over the past 15 yrs [9]. The increasing interest in this topic is clear from the increasing number of published papers over time (fig. 1); research of literature published in the period 1983-2007 (keywords: non invasive mechanical ventilation; non invasive mechanical ventilation and acute respiratory failure) found 1,024 (233 reviews) and 269 (83 reviews) references, respectively. Indeed, a study in 349 intensive care units in 23 countries describing current mechanical ventilation practices and assessing the influence of interval randomised trials when compared with findings from a 1998 cohort found that the use of NPPV increased in 2004 (11.1 versus 4.4\%) [10]. The present review will focus on recent developments in the application of NPPV in the treatment of acute and acute-onchronic respiratory failure.

Different conditions leading to acute or acute-on-chronic respiratory failure have been treated with NPPV, but only a few are supported by strong evidence, as follows: prevention of ETI in patients with acute exacerbations of chronic obstructive pulmonary disease (AECOPD) or acute cardiogenic pulmonary oedema (CPO); in immunocompromised patients; as a means of weaning from invasive mechanical ventilation in patients with AECOPD who undergo ETI. Weaker evidence supports the use of NPPV: for patients with post-operative or post-extubation ARF; for patients with ARF due to asthma exacerbations, pneumonia, acute lung injury (ALI) or acute respiratory distress syndrome (ARDS); during bronchoscopy; or as a means of pre-oxygenation before ETI in critically ill patients with severe hypoxaemia (table 2) [11]. The goals of
NPPV may be different according to the underlying pathologies. During AECOPD or acute asthma, the goal is to reduce hypercapnia by unloading the respiratory muscles and increasing alveolar ventilation, thereby improving respiratory acidosis until the underlying problem can be reversed. In acute $\mathrm{CPO}$, the goal of NPPV is to improve oxygenation, reduce the work of breathing and increase cardiac output. During hypoxaemic $\mathrm{ARF}$, the goal is to ensure adequate arterial oxygen tension $\left(\mathrm{Pa}, \mathrm{O}_{2}\right)[7]$.

\section{ACUTE EXACERBATIONS OF CHRONIC OBSTRUCTIVE PULMONARY DISEASE}

Several prospective, randomised controlled trial (RCTs) [1219], systematic reviews and meta-analyses [20-22] show a good level of evidence for the clinical efficacy of NPPV in the treatment of acute-on-chronic respiratory failure due to AECOPD. Compared with standard medical therapy alone, NPPV improved survival, reduced the need for ETI and the rate of complications, and shortened the hospital and intensive care unit (ICU) length of stay. Based on these observations, NPPV has been proposed as the first-line ventilatory strategy in this condition with different timing and location according to the level of ARF severity (fig. 2) [23, 24].

\section{Severity of ARF}

In patients with "mild" AECOPD without respiratory acidosis ( $\mathrm{pH}>7.35)$, NPPV did not prove to be more effective than standard medical therapy in preventing the occurrence of ARF, and in improving mortality and length of hospitalisation. Furthermore, $>50 \%$ of the patients did not tolerate NPPV [13, 25]. In patients with mild-to-moderate ARF, as indicated by $\mathrm{pH}$ levels 7.30-7.35, NPPV was successfully administered in different settings, including on the ward, in order to prevent ETI [18]. In more severely ill patients $(\mathrm{pH}<7.25)$, the rate of NPPV failure was inversely related to the severity of respiratory acidosis, rising to $52-62 \%[15,17]$. The use of NPPV as an alternative to ETI did not affect the mortality rate and the duration of ventilatory support, but the patients treated with NPPV experienced a lower rate of complications (VAP, difficult weaning). Even in severe patients, although exposed to higher risk of failure, an NPPV trial may be justified if ETI is not strictly required due to the need of protecting the airways and preventing loss of consciousness or gasping [15, 17, 19], provided that facilities for ETI are promptly available.

Severe encephalopathy was considered a contraindication to NPPV based on the concern that a depressed sensorium would predispose the patient to aspiration [3]. More recently, some observations of effective (" not harmful") NPPV use in patients with altered levels of consciousness due to hypercapnic ARF were reported $[26,27]$. In a recent prospective case-control multicentre study of patients with AECOPD and moderate-tosevere hypercapnic encephalopathy, the use of NPPV versus conventional (invasive) mechanical ventilation (CMV) was associated with similar short- and long-term survivals, fewer nosocomial infections and shorter durations of mechanical ventilation and hospitalisation in the subgroup of patients treated successfully with NPPV [28]. SCALA et al. [28] suggested an initial cautious NPPV trial in patients with AECOPD and hypercapnic encephalopathy, as long as there are no other contraindications and the technique is administered by an 


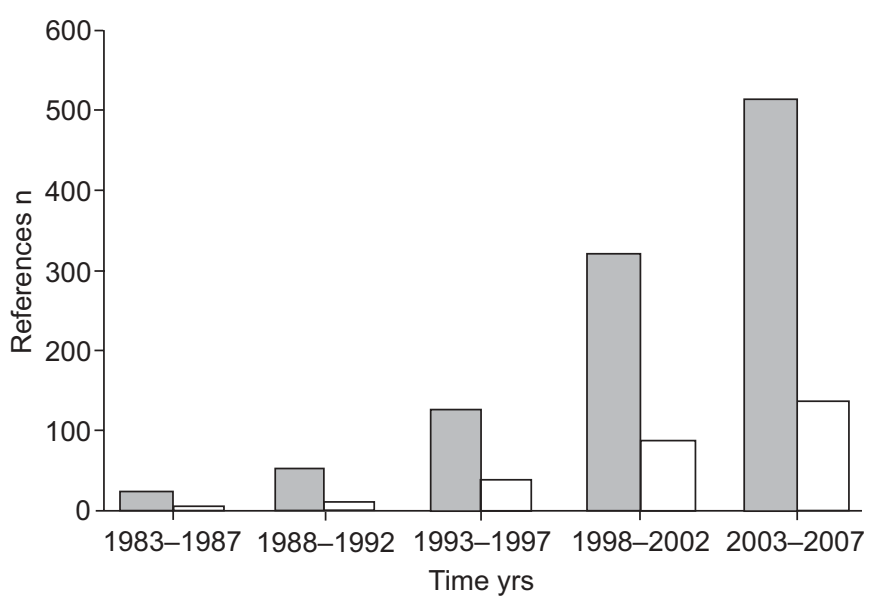

FIGURE 1. Time course of published references on noninvasive (NIV) mechanical ventilation $(\square)$, and NIV mechanical ventilation and acute respiratory failure ( $\square)$. Source: PubMed. Update: December, 2007.

experienced team in a closely monitored setting where ETI is always readily available. Despite this enthusiasm, the current authors feel that larger RCTs, which compare NPPV with CMV among patients with AECOPD presenting with different levels of consciousness and managed in a similar setting, are necessary before these observations translate into routine management.

\section{ASTHMA}

In contrast to AECOPD, the use of NPPV in severe exacerbations of asthma leading to ARF is supported by less evidence. MEDURI et al. [29] reported successful use of NPPV in 17 episodes of status asthmaticus. Mean $\mathrm{pH}$ was 7.25, confirming severe ARF, and NPPV resulted in a rapid improvement in physiological variables; only two patients required ETI. A retrospective noncontrolled study reported favourable outcomes in 22 patients with status asthmaticus treated with NPPV due to persistent hypercapnia [30]. Two other RCTs have reported inconclusive results [31, 32]. As a result of the small sample size of these studies, a recent Cochrane analysis concluded that evidence for use of NPPV in acute asthma was "promising" but "controversial" [33]. According to the British Thoracic Society Standards of Care Committee Statements: "NPPV should not be used routinely in acute asthma, but a trial might be considered in patients not promptly responding to standard treatments"'[34].

\section{HYPOXAEMIC ACUTE RESPIRATORY FAILURE}

Several non-chronic obstructive pulmonary disease (COPD) diseases may lead to hypoxaemic ARF, which is defined by a $\mathrm{Pa}_{\mathrm{O}} \mathrm{O}_{2}$ /oxygen inspiratory fraction $\left(\mathrm{FI}, \mathrm{O}_{2}\right)$ ratio $\leqslant 300 \mathrm{mmHg}$. This condition is a greater challenge than AECOPD for treatment with NPPV. A recent prospective survey conducted in 70 French ICUs highlighted a possible increase in mortality rate in the subgroup of patients with de novo hypoxaemic ARF not related to acute CPO or AECOPD and treated with NPPV, perhaps due to delayed ETI [35]. Owing to the very large spectrum of causes, results of studies on hypoxaemic ARF are difficult to apply to individual patients as frequent failure in a subset of patients may obscure success in another [36].
Therefore, the following subsets of patients will be considered: acute cardiogenic pulmonary oedema; pneumonia; acute lung injury/acute respiratory distress syndrome; and post-operative respiratory failure.

\section{Acute cardiogenic pulmonary oedema}

The use of NPPV in acute CPO is supported by RCTs [37-47] and meta-analyses [48-52]. Both mask CPAP and NPPV (inspiratory combined with positive end-expiratory pressure (PEEP); so-called bi-level ventilation) reduce ETI rate and, with a lower level of evidence, mortality rate, compared with standard medical therapy and oxygen. CPAP resulted in easier and less expensive application, and a meta-analysis suggests a greater efficacy in reducing mortality for this modality [51]. However, some studies [38, 39] suggest that NPPV may be preferable for patients with persisting dyspnoea or hypercapnia after initiation of CPAP, whereas early concerns about possible greater risks of myocardial infarction with NPPV [38] were not confirmed [53]. The main physiological benefit of CPAP in these patients is related to decreased left ventricular pre-load and afterload owing to increased intrathoracic pressure, resulting in improved cardiac performance; an increase in functional residual capacity reopens collapsed alveoli and improves oxygenation. This also reduces work of breathing [54].

\section{Pneumonia}

NPPV seems disappointing in ARF owing to pneumonia [55, 56], showing failure rates of up to $66 \%$ in patients with severe community-acquired pneumonia (CAP) [57]. An RCT of patients with severe CAP showed that NPPV reduced ETI rates, ICU length of stay and 2-month mortality rate, but only in the subgroup with underlying COPD [58]. Another RCT of patients with hypoxaemic ARF [59] showed that NPPV reduced the need for ETI among patients with pneumonia, but a more recent RCT [60], in which NPPV was used as an alternative to ETI in patients with various types of ARF, found that in the subgroup with pneumonia the technique was very unsuccessful. These data do not support the routine use of NPPV in patients with severe pneumonia. However, a cautious trial of NPPV may be considered in patients with pneumonia and underlying COPD under careful monitoring and in the appropriate setting.

Due to the risk of leakage from the mask interface, with subsequent transmission of severe acute respiratory syndrome to healthcare workers, the use of NPPV in such patients requiring mechanical ventilation was not recommended [61]. Nevertheless, promising results with NPPV in this condition have been reported in two studies [62,63].

\section{Acute lung injury/acute respiratory distress syndrome}

The effectiveness of NPPV in the treatment of ALI/ARDS has been investigated by few studies [59, 64]. The mechanism of action of NPPV in ALI/ARDS has been evaluated in a physiological study [65]. Mask pressure support combined with PEEP is needed to unload inspiratory muscles, whereas in this setting CPAP alone improves oxygenation but fails to unload the respiratory muscles. Studies of NPPV for the treatment of ALI/ARDS have reported failure rates ranging 50-80\%, but no RCTs have focused on ALI/ARDS exclusively. Independent risk factors for NPPV failure in this group of 


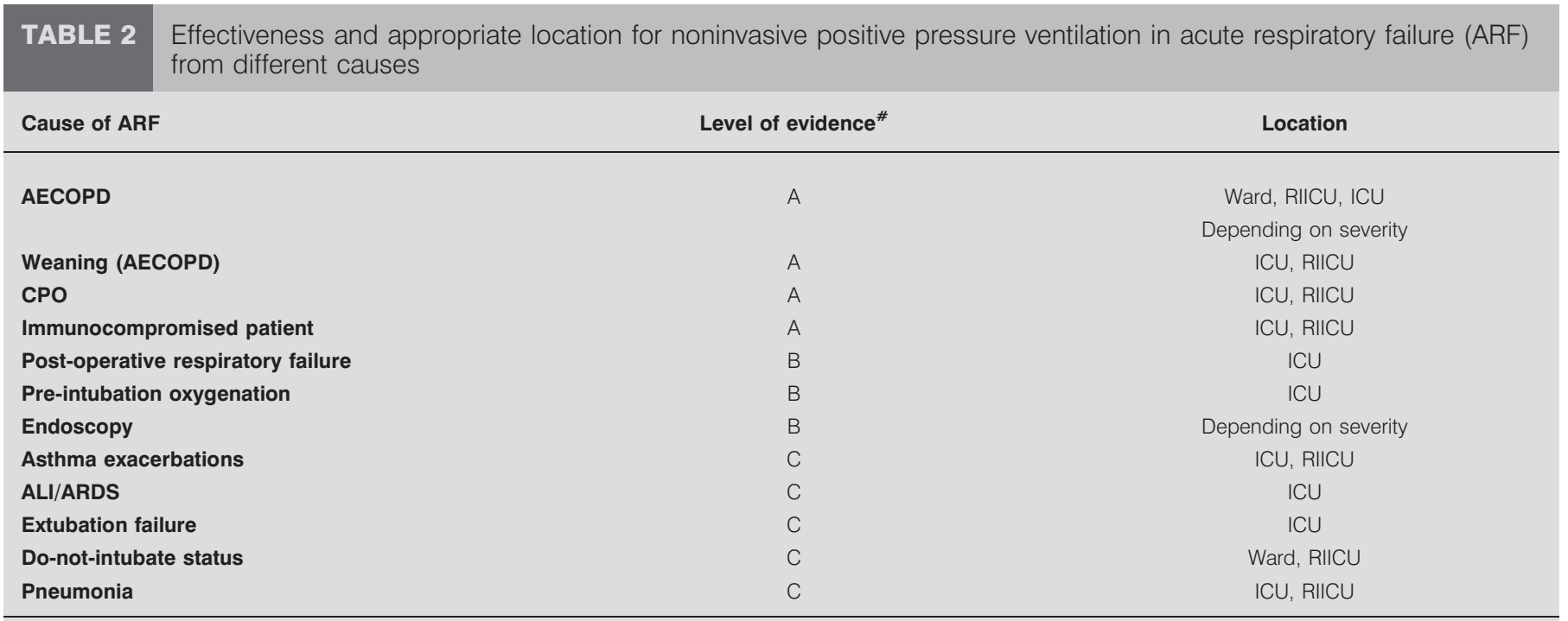

Evidence A: multiple randomised controlled trials and meta-analyses; evidence B: more than one randomised controlled trial, case-control series or cohort studies evidence; C: case series or conflicting data. AECOPD: acute exacerbation of chronic obstructive pulmonary disease; RIICU: respiratory intermediate intensive care unit;

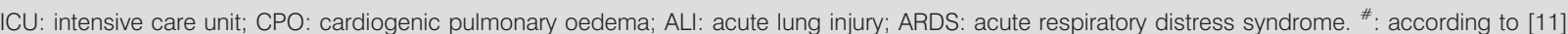

patients include severe hypoxaemia, shock and metabolic acidosis [64]. A recent meta-analysis reported no reduction in the ETI rate and ICU mortality rate with the addition of NPPV to standard care [66]. Conclusions are difficult to draw owing to the heterogeneity of the studies analysed. A recent multicentre European survey reported the application of NPPV as a first-line intervention in patients with early ARDS, describing what happens in everyday clinical practice in three European ICUs having expertise with NPPV [67]. The technique improved gas exchange and avoided ETI in 54\% of patients. Avoidance of ETI was associated with less VAP and a lower ICU mortality rate. Need for ETI was more likely in older

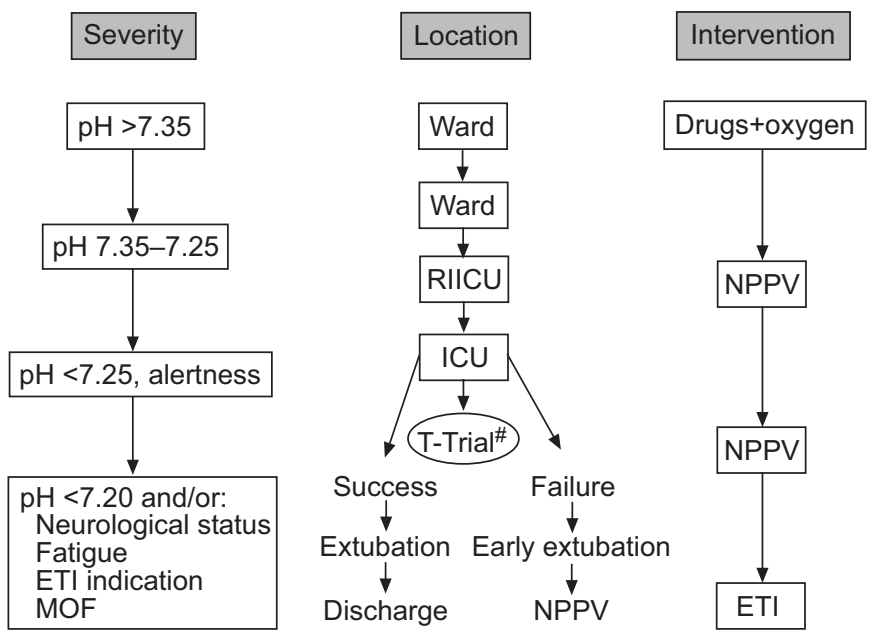

FIGURE 2. Flow chart of the application of noninvasive positive pressure ventilation (NPPV) in acute exacerbations of chronic obstructive pulmonary disease, according to the severity of acute respiratory failure. RIICU: respiratory intermediate intensive care unit; ICU: intensive care unit; ETI: endotracheal intubation; MOF: multiple organ failure. ${ }^{*}$ : as described in [81] patients, with a higher Simplified Acute Physiology Score (SAPS) II and severe hypoxaemia, or when a higher level of PEEP and pressure support was needed [67]. NPPV cannot be recommended as routine therapy for ALI/ARDS. A cautious trial in highly selected patients with less severe general conditions can be attempted in an appropriate location. The use of NPPV should not delay ETI, in case of further deterioration or failure to improve [68].

\section{Post-operative respiratory failure}

Both CPAP and NPPV have been successfully used in the postoperative period [69]. Compared with standard treatment, noninvasive CPAP used after major abdominal surgery or thoracoabdominal aneurysm repair improves hypoxaemia and reduces the incidence of complications, such as pneumonia, atelectasis and the need for ETI [70, 71]. Patients with hypoxaemic ARF after lung resection needed less ETI and showed reduced mortality rates if treated with NPPV compared with standard management [72]. Despite there being few studies that have examined different techniques following various surgeries, NPPV should be considered to be among the recommended options for post-surgical patients.

NPPV can play an important role in preventing post-operative pulmonary complications in high-risk patients using chronic ventilators as a consequence of restrictive lung pathology [73].

\section{TRANSPLANTATION AND IMMUNOCOMPROMISED PATIENTS}

A small, single-centre study [74] showed that NPPV also has a role in ARF after solid organ transplantation (liver, lung, renal). RCTs in transplant recipients with haematological diseases and hypoxaemic ARF have shown decreased ETI and ICU mortality rates and shorter ICU lengths of stay in patients treated with NPPV as compared with conventional therapy [75]. An RCT in patients with ARF and immunosuppression from various causes reported lower mortality and ETI rates in the subgroup 
of patients treated with NPPV compared with standard treatment. The reduction in mortality was mainly related to the reduction in ETI rate and in the risk of VAP [76]. Similar findings have been reported by a nonrandomised study in patients with AIDS [77]. The reduced mortality rate is likely to be related to reduced infectious complications associated with NPPV compared with ETI, including VAP, other nosocomial infections and septic shock [78]. These findings support NPPV as the preferred initial ventilatory modality for these patients to avoid ETI and its associated risks.

\section{WEANING FROM INVASIVE MECHANICAL VENTILATION IN PATIENTS WITH AECOPD}

NPPV has been proposed as a means of facilitating weaning from invasive mechanical ventilation in patients with AECOPD and acute on chronic respiratory failure failing a single [79, 80] or repeated T-piece trial [81]. In extubated patients who were switched to NPPV and weaned according to a standard protocol using pressure support ventilation, RCTs showed increased weaning rates, decreased duration of mechanical ventilation and ICU stay, and reduced rates of VAP compared with CMV. A meta-analysis of studies comparing "usual" weaning strategies to early extubation with immediate application of NPPV, confirmed that switch to NPPV resulted in a favourable outcome, including lower mortality rate, lower rate of VAP and shorter total time of mechanical ventilation [82]. The physiopathological basis underlying these results is that NPPV is as capable as invasive ventilation for unloading respiratory muscles and improving gas exchanges; however, this can only partially explain the success of this technique in weaning [83]. Based on these findings, patients intubated for hypercapnic ARF due to AECOPD who fail spontaneous breathing trials should be considered for a trial of extubation to NPPV.

\section{POST-EXTUBATION RESPIRATORY FAILURE NPPV to treat post-extubation failure}

Extubation failure is associated with high morbidity and mortality. Despite a promising previous case-control study in hypercapnic patients [84], an RCT found no reduction in re-intubations among patients who developed ARF within $48 \mathrm{~h}$ of extubation [85]. In an RCT evaluating the use of NPPV (compared with standard therapy), as soon as patients $(10 \%$ with COPD) developed signs of respiratory distress [86], NPPV failed to reduce re-intubations and resulted in increased ICU mortality, possibly related to delays in re-intubation. These findings do not support the use of NPPV as a means of treatment of respiratory failure after extubation. The promising results in hypercapnic patients reported in a previous study [84] need confirmation since there would be still a rationale for using NPPV in this subset of patients.

\section{NPPV to prevent post-extubation failure}

Two other RCTs $[87,88]$ carried out on patients at high risk for extubation failure found that NPPV, applied immediately after extubation, prevented ARF and reduced the need for reintubation and ICU mortality, with the subset of COPD patients showing the most benefit [88]. NPPV has also been successfully used for the prevention of ARF in the first $48 \mathrm{~h}$ post-extubation in severely obese patients [89]. These data support the use of NPPV as a means of prevention of ARF in patients at high risk of extubation failure, in selected patients and in appropriate settings allowing for strict monitoring and prompt ETI. Routine use in all patients is discouraged [90].

\section{DO-NOT-INTUBATE PATIENTS}

NPPV is being increasingly used as an alternative to invasive ventilation in end-stage symptomatic patients [91-95]. A recent European survey in respiratory intermediate intensive care units (RIICU) has shown that NPPV was used as the ceiling of ventilatory care in almost a third of the patients [96]. Clinical trials have recently underlined and confirmed [97, 98] the role of NPPV as an effective alternative to ETI in patients with chronic disease and poor life expectancy (with or without COPD), showing that this ventilatory technique may favourably reduce dyspnoea shortly after initiation even without an associated episode of hypercapnic ARF. The Society of Critical Care Medicine recently initiated a Task Force to develop an approach for considering the use of NPPV for patients who choose to forego ETI [99]. The use of NPPV for patients with ARF could be classified into three categories: 1) NPPV as life support with no pre-set limitations on life-sustaining treatments; 2) NPPV as life support when patients and families have decided to forego ETI; and 3) NPPV as a palliative measure when patients and families have chosen to forego all life support, receiving comfort measures only. The Task Force suggested an approach to use NPPV for patients and families who choose to forego ETI. NPPV should be applied after careful discussion of the goals of care, with explicit parameters for success and failure, by experienced personnel, and in appropriate healthcare settings [99].

The use of NPPV in these extreme circumstances should bear in mind ethical, legal and religious issues. A Spanish study concluded that the use of NPPV offers very low expectations in medium-term survival in do-not-intubate (DNI) patients. The main reason may be that in a country with little experience in advanced directives, the DNI statement coincides with the final stages of disease progression [100].

\section{FIBREOPTIC BRONCHOSCOPY}

Confirming a previous preliminary study [101], an RCT has shown that in severe hypoxaemic patients mask CPAP reduces the risk of ARF following bronchoscopy [102]. Another RCT in hypoxaemic patients undergoing bronchoscopy showed that NPPV increased $\mathrm{Pa}, \mathrm{O}_{2} / \mathrm{FI}_{1} \mathrm{O}_{2}$, whereas patients randomised to conventional oxygen therapy suffered from a worsening in oxygenation [103]. NPPV has also been reported to be useful in performing successful bronchoscopy in hypercapnic COPD patients with pneumonia [104]. Flexible bronchoscopy in spontaneously breathing young children was associated with significant decreases in tidal volume and respiratory flow, which were reversed by CPAP [105]. The use of NPPV during fibreoptic bronchoscopy is supported by previous evidence and should be considered for use, especially when risks of ETI are high, such as in immunocompromised patients. However, besides competency in endoscopy and in NPPV use, an expert team should be offered the availability of emergent intervention.

\section{SUCCESSFUL NPPV}

Successful use of NPPV in ARF depends on several factors, some of which are listed hereafter in order of importance according to the present authors' experience. 


\section{Clinical conditions}

As in all fields of medicine, the selection of appropriate patients (evidence supported indications) no contraindications, is key to the successful application of NPPV. Most of the contraindications to NPPV listed in table 3 are derived from exclusion criteria for the RCTs. Therefore, it is more correct to state that NPPV is not proven in these circumstances [106]. The use of predictive factors may be useful in the choice of this modality, although, at the end, clinical judgment is important for decision-making. An improvement in arterial blood gases and in sensorium, as assessed by means of the KELLY and MATTHAY score [107], the Glasgow Coma Scale, or the response of a combination of several clinical and physiological parameters to NPPV after the first 1-2 h of NPPV, are used as predictors of success or failure in COPD patients [108-110]. Failure of predictors, as well as presence of contraindications, as listed in table 3, may be considered as criteria for discontinuation of NPPV and intubation or re-intubation. Another issue in the success/failure probability is represented by airway colonisation by nonfermenting Gram-negative bacilli, which is strongly associated with NPPV failure [111]. Nevertheless, even when initially successful, COPD patients with severe ARF treated with NPPV, particularly those with more severe functional impairment during the stable state, may have a late worsening (after $>48 \mathrm{~h}$ ), often requiring ETI, despite an initial brief improvement [112]. Even more difficult is the prediction of NPPV success/failure in hypoxaemic ARF. Predictors of failure were considered to be a SAPS II $<34$ and $\mathrm{Pa}_{1} \mathrm{O}_{2} / \mathrm{FI}_{1} \mathrm{O}_{2}<175 \mathrm{mmHg}$ after the first hour of NPPV in ALI/ ARDS [68]. In general, NPPV is more likely to also be successful in different conditions leading to hypoxaemic ARF when hypercapnia is present [11].

\section{Trained team}

As in all fields of therapy, NPPV application also follows a learning curve. It has been reported that as caregivers become more confident with NPPV, success rates remain stable despite increasing severity of ARF [113]. A retrospective cohort study in 26 French medical ICUs [114] found that training in NPPV implementation may be an important factor in improving survival and reducing nosocomial infections in critical patients with AECOPD or CPO. Rather interestingly, JOLLIET et al. [57] also reported $10 \mathrm{yrs}$ later that NPPV was not as time consuming as previously reported in 1991 [115].

TABLE 3 Reported contraindications for noninvasive
ventilation

\section{Monitoring and location}

Close monitoring is crucial, especially during the initial period of NPPV (table 4). The main concepts for adequate monitoring of patients under NPPV can be summarised by: strict nurse supervision of respiratory and neurological conditions of the patient; noninvasive monitoring of oxygen saturation, cardiac frequency or electrocardiogram and blood pressure; and preference for ventilators with availability of monitoring airway pressures, expired volume and airflow. The problem of monitoring is strictly related to NPPV location, which can actually determine NPPV outcome. Treating a severe hypoxaemia with or without hypercapnia might be even more dangerous in a general ward, whereas it is safer in a monitored high-technology setting, such as in an ICU. In other words, the selection of patients must take into account the location available in which to perform NPPV (table 2; fig. 2) [116]. Several RCTs support the effectiveness of NPPV in the ICU, the RIICU, the general ward and the emergency department [117]. Despite the demonstrated success of NPPV, at least in some clinical conditions, the utilisation rates for NPPV vary enormously among different acute care hospitals within the same region [118]. The perceived reasons for lower utilisation rates reported in the study [118] included lack of physician knowledge, insufficient respiratory therapist training and inadequate equipment. In a survey of NPPV practice in Ontario, Canada [119], the two most common indications for NPPV use were COPD and congestive heart failure. NPPV guidelines, protocols or policies were available in 12 out of 15 hospitals. There was variation in NPPV utilisation among specialties but not hospitals. Specialty (critical care and respirology versus internal and emergency medicine), fewer years of postgraduate experience and a greater number of noninvasive ventilators were predictors of more frequent NPPV use. Only $6 \%$ of respondents reported initiation of use and continued use most frequently in non-monitored settings, which increased with the number of noninvasive ventilators. Physician characteristics, such as awareness of the literature, were predictive of NPPV use for AECOPD, whereas perceived NPPV efficacy was predictive of use for many indications, including congestive heart failure. Recently, a case series also reported effectiveness of the NPPV treatment in patients with moderate-to-severe ARF ( $\mathrm{pH}<7.25$ ) as a result of AECOPD in general ward settings [120]. Given the prevalence of patients presenting with severe respiratory acidosis, further studies are needed to better outline the role of NPPV in non-ICU settings.

\section{Interface}

The interface is one of the crucial issues affecting NPPV outcome; poor mask tolerance, skin lesions and leaks are reported to be among factors causing NPPV failure and the need for ETI [11]. Although the face mask is usually considered the first choice interface for delivering NPPV in the acute setting, nasal masks were reported to have similar success rates but higher tolerability than oro-nasal techniques in ARF [121]. More recently, a helmet has been introduced to deliver NPPV, reducing discomfort, pressure necrosis of the skin, eye irritation and gastric distension. Some mechanical characteristics of the helmets, which are primarily large volume and highly compliant soft collar compared with the face masks, might, however, impair patient-ventilator interaction. In normal volunteers, during helmet NPPV application, an 


\begin{tabular}{|c|c|}
\hline Sensorium & KELLY and MATTHAY [107] scale, Glasgow Coma Scale \\
\hline Dyspnoea & Borg Scale, Visual Analogue Scale \\
\hline Respiratory rate & Clinical, ventilator monitor \\
\hline Mask comfort & Clinical \\
\hline Compliance with ventilator setting & Clinical \\
\hline Vital signs & Clinical \\
\hline \multicolumn{2}{|l|}{ Physiology } \\
\hline Arterial oxygen saturation & Pulse oximetry, arterial blood gas sample (frequently during first hours) \\
\hline Arterial blood pressure & Clinical, monitoring (noninvasive) \\
\hline Set parameters & Ventilator monitor \\
\hline
\end{tabular}

increase in delay time and in futile inspiratory efforts was observed [122]. When a resistive load was imposed, the inspiratory effort and patient-ventilator asynchrony increased and $\mathrm{CO}_{2}$ clearance worsened [123, 124]. In one study, helmet and face mask were equally tolerated and both were effective in improving gas exchange and decreasing inspiratory effort [125]. The helmet, however, was less efficient in decreasing inspiratory effort and worsened the patient-ventilator interaction [125]. A recent report suggests the need for dedicated monitoring and alarming systems when using helmet CPAP to reduce the danger due to accidental failure of fresh gas source supply [126]. Regardless of the interface used, there is the need to reduce the risk of transmission of respiratory tract infections, such as careful fitting on the face, with potential risks for the caregivers. The addition of a viral-bacterial filter to the NPPV system between the mask and the exhalation port has been proposed [127].

\section{Ventilatory setting}

In theory, NPPV could be delivered with similar modalities as through an endotracheal or a tracheostomy cannula. In real life, the circumstances of ventilation and the equipment available are different [128]. Mask ventilation is now almost exclusively delivered by pressure-cycled ventilators (usually in pressure support or so-called bi-level ventilation), although no differences in success rate were found when NPPV was applied by means of volume-cycled ventilators [129]. In addition, PAV (a mode of partial ventilatory assistance endowed with characteristics of proportionality and adaptability to the intensity and timing of spontaneous ventilatory patterns) was used as an experimental modality of NPPV. Mask PAV was effective in improving arterial blood gases and reducing work of breathing in severe AECOPD [130], but it was not clinically superior to mask pressure support in multicentre studies [131, 132]. It seems that in real life this modality has no role in the routine NPPV treatment of ARF.
There is no definite guideline on optimal ventilator settings. The theoretical level of inspiratory and expiratory pressures to be applied in different diseases (e.g. peak inspiratory pressure support to increase tidal volume and PEEP to compensate for threshold load imposed by intrinsic PEEP in COPD patients) may not be the same as that applied through an ETI or a mask. The decision must take into consideration the ability to reduce work of breathing by providing an adequate level of pressure support against the discomfort and greater air leakage imposed by higher pressures. In fact, the patient's compliance with the ventilatory setting is the key factor influencing the choice of parameters [133].

\section{Leaks and ventilators: ICU versus home}

The presence of gas leaks is a near-constant feature of NPPV and may affect triggering of the ventilator, delivered $\mathrm{FI}_{\mathrm{I}} \mathrm{O}_{2}$ and air humidification. Differences can be found depending on the ventilator used (home versus ICU ventilators). In this regard, the importance of the inspiratory flow rate setting to reduce the leaks must be stressed [134]. While home ventilators can adequately compensate large gas leaks, ICU ventilators are not able to cope with large leaks and need to titrate trigger sensitivity to avoid auto-triggering and asynchrony between patient and ventilator [135-137]. Indeed, the presence of asynchrony represents one of the main problems with NPPV both during ARF episodes [138] and in long-term ventilation for chronic respiratory insufficiency [139]. In this regard, the recording of breathing frequency using the ventilator monitor may be misleading. Conversely, home ventilators usually have no facility to monitor the delivered $\mathrm{FI}_{1} \mathrm{O}_{2}$, which is crucial during hypoxaemic ARF. The results of a bench-model study [140] confirm that leaks interfere with several key functions of ICU ventilators. Overall, NPPV modes can correct part or all of this interference, but with wide variations between machines in terms of efficiency. Clinicians should be aware of these differences when applying NPPV with an ICU ventilator. Ventilators designed for NPPV should be used. The use of 
conventional ventilators designed for invasive ventilation should be strongly discouraged, since failure rates are inappropriately high. In any case, as stated previously, ventilators with the availability of monitoring of functions, such as airway pressures, tidal volume and airflow, are preferable.

\section{Humidification}

In normal subjects, heated humidification during nasal NPPV attenuates the adverse effects of mouth leak on effective tidal volume and nasal resistance, and improves overall comfort. Heated humidification should be considered as part of an approach to patients who are troubled with nasal symptoms, once the leak has been minimised [141]. Two humidifying devices are used with ICU ventilators: 1) heated humidifiers $(\mathrm{HH})$; and 2) heat-moisture exchangers (HME). A physiological study suggests that, compared with $\mathrm{HH}$, HME greatly increases work of breathing during NPPV in hypercapnic ARF [128]. Indeed, it has been shown that during NPPV, the increased dead space of an HME can negatively affect ventilatory function and gas exchange and decrease efficiency of NPPV in patients with ARF [142]. During helmet ventilation, humidification may be difficult, if not impossible.

\section{COST-EFFECTIVENESS}

According to the studies previously conducted in the ICU, NPPV may reduce the risk of intubation from 63 to $21 \%$ and the mortality rate from 25 to $9 \%$ in AECOPD; the numbers needed to treat (NNT) were 2.4 to prevent one ETI and 6.3 to prevent one death. Application of NPPV in the ward was found to reduce the probability of meeting criteria for ETI from 27 to $15 \%$, and the real ETI rate from 11 to $6 \%$; the NNT was 8.3 to prevent criteria for ETI and 20 to prevent real ETI [143]. NPPV has been shown to be cost effective in the ICU, resulting in an improved clinical outcome and reduced costs [144]. NPPV use in the ward also reduces mortality, the demand for intensive care and lowers the overall cost of treatment [145]. Studies specifically addressing the workload for the personnel working with NPPV found that the first $6-8 \mathrm{~h}$ are usually associated with a high level of workload, reflecting the need for the personnel to remain at the bedside until the patient has adapted to the ventilation $[6,18]$. The implications of NPPV regarding financial and human resources compared with CMV are still unclear. There is evidence that some COPD patients with less severe ARF without failure of any other organ may be successfully treated with lower costs in the RIICU and even in the ward than in the ICU (fig. 2) [146].

\section{WHAT'S NEW?}

\section{Helium-oxygen mixture}

The use of a helium-oxygen mixture (heliox) during NPPV in AECOPD seems very promising in further reducing dyspnoea and work of breathing, as well as hospital length of stay, but not in improving the success rate [147-150]. The use of heliox is difficult due to the lack of availability of an approved helioxdelivery system, and appropriately designed RCTs are needed to define the role for heliox combined with NPPV in COPD patients [151].

\section{Sedation}

Despite the advantages of NPPV, in ARF a large number of failures are due to patient refusal to continue the often uncomfortable sessions. Therefore, sedation might have a role in the success of this procedure. A cross-sectional web-based survey [152] showed that most physicians infrequently use sedation and analgesic therapy for NPPV to treat ARF, but practices vary widely within and between specialties and geographic regions. A recent pilot study [153] shows that remifentanil-based sedation is safe and effective in the treatment of NPPV failure due to low tolerance.

\section{CONCLUSIONS}

Noninvasive positive pressure ventilation has assumed an important role in managing patients with acute respiratory failure. Even in conditions in which noninvasive positive pressure ventilation has strong evidence of success, patients should be monitored closely for signs of treatment failure and should be promptly intubated before a crisis develops. The application of noninvasive positive pressure ventilation by a trained and experienced team, with careful patient selection and choice of appropriate location and setting, should optimise patient outcomes. It should be made clear that noninvasive positive pressure ventilation is not a panacea nor the "poor man's" technique of mechanical ventilation. Conversely, it cannot replace endotracheal intubation in all circumstances.

\section{REFERENCES}

1 Laghi F, Tobin MJ. Indications for mechanical ventilation. In: Tobin MJ, ed. Principles and Practice of Mechanical Ventilation. 2nd Edn. New York, McGraw-Hill, 2006; pp. 129-162.

2 Epstein SK. Complications associated with mechanical ventilation. In: Tobin MJ, ed. Principles and Practice of Mechanical Ventilation. 2nd Edn. New York, McGrawHill, 2006; pp. 877-902.

3 Hill NS. Noninvasive positive pressure ventilation. In: Tobin MJ, ed. Principles and Practice of Mechanical Ventilation. 2nd Edn. New York, McGraw-Hill, 2006; pp. 433-471.

4 Girou E, Schortgen F, Delclaux C, et al. Association of noninvasive ventilation with nosocomial infections and survival in critically ill patients. JAMA 2000; 284: 2361-2367.

5 Hess DR. Noninvasive positive pressure ventilation and ventilator-associated pneumonia. Respir Care 2005; 50: 924-929.

6 Nava S, Evangelisti I, Rampulla C, Compagnoni ML, Fracchia C, Rubini F. Human and financial costs of noninvasive mechanical ventilation in patients affected by COPD and acute respiratory failure. Chest 1997; 111: 1631-1638.

7 Mehta S, Hill NS. Noninvasive ventilation. Am J Respir Crit Care Med 2001; 163: 540-577.

8 International Consensus Conference in Intensive Care Medicine: noninvasive positive pressure ventilation in acute respiratory failure. Am J Respir Crit Care Med 2001; 163: 283-291.

9 Garpestad E, Brennan J, Hill NS. Noninvasive ventilation for critical care. Chest 2007; 132: 711-720.

10 Esteban A, Ferguson ND, Meade MO, et al. Evolution of mechanical ventilation in response to clinical research. Am J Respir Crit Care Med 2008; 177: 170-177. 
11 Hill NS, Brennan J, Garpestad E, Nava S. Noninvasive ventilation in acute respiratory failure. Crit Care Med 2007; 35: 2402-2407.

12 Bott J, Carroll MP, Conway JH, et al. Randomized controlled trial of nasal ventilation in acute ventilatory failure due to chronic obstructive airways disease. Lancet 1993; 341: 1555-1557.

13 Barbe F, Togores B, Rubi M, Pons S, Maimo A, Agusti AG. Noninvasive ventilatory support does not facilitate recovery from acute respiratory failure in chronic obstructive pulmonary disease. Eur Respir J 1996; 9: 1240-1245.

14 Celikel T, Sungur M, Ceyhan B, Karakurt S. Comparison of non-invasive positive pressure ventilation in acute respiratory failure. Chest 1998; 114: 1636-1642.

15 Conti G, Antonelli M, Navalesi P, et al. Noninvasive versus conventional mechanical ventilation in patients with chronic obstructive pulmonary disease after failure of medical treatment in the ward: a randomized trial. Intensive Care Med 2002; 28: 1701-1707.

16 Kramer N, Meyer TJ, Meharg J, Cece RD, Hill NS. Randomized, prospective trial of noninvasive positive pressure ventilation in acute respiratory failure. Am J Respir Crit Care Med 1995; 151: 1799-1806.

17 Brochard L, Mancebo J, Wysocki M, et al. Noninvasive ventilation for acute exacerbations of chronic obstructive pulmonary disease. $N$ Engl J Med 1995; 333: 817-822.

18 Plant PK, Owen JL, Elliott MW. Early use of non-invasive ventilation for acute exacerbations of chronic obstructive pulmonary disease on general respiratory wards: a multicentre randomized controlled trial. Lancet 2000; 355: 1931-1935.

19 Squadrone E, Frigerio P, Fogliati C, et al. Noninvasive versus invasive ventilation in COPD patients with severe acute respiratory failure deemed to require ventilatory assistance. Intensive Care Med 2004; 30: 1303-1310.

20 Ram FS, Picot J, Lightowler J, Wedzicha JA. Non-invasive positive pressure ventilation for treatment of respiratory failure due to exacerbations of chronic obstructive pulmonary disease. Cochrane Database Syst Rev 2004; 3: CD004104.

21 Keenan SP, Sinuff T, Cook DJ, Hill NS. Which patients with acute exacerbation of chronic obstructive pulmonary disease benefit from noninvasive positive pressure ventilation? A systematic review of the literature. Ann Intern Med 2003; 138: 861-870.

22 Lightowler JV, Wedzicha JA, Elliott MW, Ram FS. Noninvasive positive pressure ventilation to treat respiratory failure resulting from exacerbations of chronic obstructive pulmonary disease: Cochrane systematic review and meta-analysis. BMJ 2003; 326: 185-189.

23 Nava S, Navalesi P, Conti G. Time of non-invasive ventilation. Intensive Care Med 2006; 32: 361-370.

24 Elliott MW. Non-invasive ventilation in acute exacerbations of chronic obstructive pulmonary disease: a new gold standard? Intensive Care Med 2002; 28: 1691-1694.

25 Keenan SP, Powers CE, McCormack DG. Noninvasive positive-pressure ventilation in patients with milder chronic obstructive pulmonary disease exacerbations: a randomized controlled trial. Respir Care 2005; 50: 610-616.
26 Díaz GG, Alcaraz AC, Talavera JC. Noninvasive positivepressure ventilation to treat hypercapnic coma secondary to respiratory failure. Chest 2005; 127: 952-960.

27 Scala R, Naldi M, Archinucci I, Coniglio G, Nava S. Noninvasive positive pressure ventilation in patients with acute exacerbations of COPD and varying levels of consciousness. Chest 2005; 128: 1657-1666.

28 Scala R, Nava S, Conti G, et al. Noninvasive versus conventional ventilation to treat hypercapnic encephalopathy in chronic obstructive pulmonary disease. Intensive Care Med 2007; 33: 2101-2108.

29 Meduri GU, Cook TR, Turner RE, Cohen M, Leeper KV. Noninvasive positive pressure ventilation in status asthmaticus. Chest 1996; 110: 767-774.

30 Fernandez MM, Villagra A, Blanch L, Fernandez R. Noninvasive mechanical ventilation in status asthmaticus. Intensive Care Med 2001; 27: 486-492.

31 Holley MT, Morrissey TK, Seaberg DC, Afessa B, Wears RL. Ethical dilemmas in a randomized trial of asthma treatment: can Bayesian statistical analysis explain the results? Acad Emerg Med 2001; 8: 1128-1135.

32 Soroksky A, Stav D, Shpirer I. A pilot, prospective, randomized, placebo-controlled trial of bilevel positive airway presure in acute asthmatic attack. Chest 2003; 123: 1018-1025.

33 Ram FS, Wellington S, Rowe BH, Wedzicha JA. Noninvasive positive pressure ventilation for treatment of respiratory failure due to severe acute exacerbations of asthma. Cochrane Database Syst Rev 2005; 1: CD004360.

34 British Thoracic Society Standards of Care Committee. Non-invasive ventilation in acute respiratory failure. Thorax 2002; 57: 192-211.

35 Demoule A, Girou E, Richard JC, Taille S, Brochard L. Benefits and risks of success or failure of noninvasive ventilation. Intensive Care Med 2006; 32: 1756-1765.

36 Meduri GU, Turner RE, Abou-Shala N, Wunderink R, Tolley E. Noninvasive positive pressure ventilation via face mask. First-line intervention in patients with acute hypercapnic and hypoxemic respiratory failure. Chest 1996; 109: 179-193.

37 Masip J, Betbesé AJ, Páez J, et al. Non-invasive pressure support ventilation versus conventional oxygen therapy in acute cardiogenic pulmonary oedema: a randomised trial. Lancet 2000; 356: 26-32.

38 Mehta S, Jay GD, Woolard RH, et al. Randomized prospective trial of bilevel versus continuous positive airway pressure in acute pulmonary edema. Crit Care Med 1997; 25: 620-628.

39 Nava S, Carbone G, Di Battista N, et al. Noninvasive ventilation in cardiogenic pulmonary edema. A multicenter, randomized trial. Am J Respir Crit Care Med 2003; 168: 1-6.

40 Bersten AD, Holt AW, Vedig AE, Skowronski GA, Baggoley CJ. Treatment of severe cardiogenic pulmonary edema with continuous positive airway pressure delivered by face mask. N Engl J Med 1991; 325: 1825-1830.

41 Lin M, Yang YF, Chiang HT, Chang MS, Chiang BN, Cheitlin MD. Reappraisal of continuous positive airway pressure therapy in acute cardiogenic pulmonary edema: short-term results and long-term follow-up. Chest 1995; 107: 1379-1386. 
42 Pang D, Keenan SP, Cook DJ, Sibbald WJ. The effect of positive airway pressure on mortality and the need for intubation in cardiogenic pulmonary edema. Chest 1998; 114: 1185-1192.

43 Park M, Sangean MC, Volpe Mde S, et al. Randomized, prospective trial of oxygen, continuous positive airway pressure, and bilevel positive airway pressure by face mask in acute cardiogenic pulmonary edema. Crit Care Med 2004; 32: 2407-2415.

44 Crane SD, Elliott MW, Gilligan P, Richards K, Gray AJ. Randomised controlled comparison of continuous positive airways pressure, bilevel non-invasive ventilation, and standard treatment in emergency department patients with acute cardiogenic pulmonary oedema. Emerg Med J 2004; 21: 155-161.

45 Bellone A, Monari A, Cortellaro F, Vettorello M, Arlati S, Coen D. Myocardial infarction rate in acute pulmonary edema: noninvasive pressure support ventilation versus continuous positive airway pressure. Crit Care Med 2004; 32: 1860-1865.

46 Bellone A, Vettorello M, Monari A, Cortellaro F, Coen D. Noninvasive pressure support ventilation versus continuous positive airway pressure in acute hypercapnic pulmonary edema. Intensive Care Med 2005; 31: 807-811.

47 Giacomini M, Iapichino G, Cigada M, et al. Short-term noninvasive pressure support ventilation prevents ICU admittance in patients with acute cardiogenic pulmonary edema. Chest 2003; 123: 2057-2061.

48 Masip J, Roque M, Sanchez B, Fernandez R, Subirana M, Exposito JA. Noninvasive ventilation in acute cardiogenic pulmonary edema. Systematic review and meta-analysis. JAMA 2005; 294: 3124-3130.

49 Ho KM, Wong K. A comparison of continuous and bilevel positive airway pressure non-invasive ventilation inpatients with acute cardiogenic pulmonary oedema: a meta-analysis. Crit Care 2006; 10: R49.

50 Collins SP, Mielniczuk LM, Whittingham HA, Boseley ME, Schramm DR, Storrow AB. The use of noninvasive ventilation in emergency department patients with acute cardiogenic pulmonary edema: a systematic review. Ann Emerg Med 2006; 48: 260-269.

51 Winck JC, Azevedo LF, Costa-Pereira A, Antonelli M, Wyatt JC. Efficacy and safety of non-invasive ventilation in the treatment of acute cardiogenic pulmonary edema: a systematic review and meta-analysis. Crit Care 2006; 10: R69.

52 Peter JV, Moran JL, Phillips-Hughes J, Graham P, Bersten AD. Effect of non-invasive positive pressure ventilation (NIPPV) on mortality in patients with acute cardiogenic pulmonary oedema: a meta-analysis. Lancet 2006; 367: 1155-1163.

53 Ferrari G, Olliveri F, De Filippi G, et al. Non-invasive positive airway pressare and risk of myocardial infarction in acute cardiogenic pulmonary edema: continuous positive airway pressure versus non-invasive positive pressure ventilation. Chest 2007; 132: 1804-1809.

54 Boehmer JP, Popjes E. Cardiac failure: mechanical support strategies. Crit Care Med 2006; 34: Suppl. 9, S268-S277.

55 Antonelli M, Conti G, Moro ML, et al. Predictors of failure of noninvasive positive pressure ventilation in patients with acute hypoxemic respiratory failure: a multi-center study. Intensive Care Med 2001; 27: 1718-1728.

56 Puha J, Kong K, Lee KH, Shen L, Lim TK. Noninvasive ventilation in hypercapnic acute respiratory failure due to chronic obstructive pulmonary disease versus other conditions: effectiveness and predictors of failure. Intensive Care Med 2005; 31: 533-539.

57 Jolliet P, Abajo B, Pasquina P, Chevrolet JC. Non-invasive pressure support ventilation in severe communityacquired pneumonia. Intensive Care Med 2001; 27: 812-821.

58 Confalonieri M, Potena A, Carbone G, Porta RD, Tolley EA, Meduri GU. Acute respiratory failure in patients with severe community-acquired pneumonia: a prospective randomized evaluation of noninvasive ventilation. Am J Respir Crit Care Med 1999; 160: 1585-1591.

59 Ferrer M, Esquinas A, Leon M, Gonzalez G, Alarcon A, Torres A. Noninvasive ventilation in severe hypoxemic respiratory failure: a randomized controlled trial. Am J Respir Crit Care Med 2003; 168: 1438-1444.

60 Honrubia T, García López FJ, Franco N, et al. Noninvasive versus conventional mechanical ventilation in acute respiratory failure. A multicenter, randomized controlled trial. Chest 2005; 128: 3916-3924.

61 Fowler RA, Guest CB, Lapinsky SE, et al. Transmission of severe acute respiratory syndrome during intubation and mechanical ventilation. Am J Respir Crit Care Med 2004; 169: 1198-1202.

62 Cheung TMT, Lau CWA, Poon E, Kong BMH, Yung RWH. Effectiveness of noninvasive positive pressure ventilation in the treatment of acute respiratory failure in severe acute respiratory syndrome. Chest 2004; 126: 845-850.

63 Han F, Jiang YY, Zheng JH, Gao ZC, He QY. Noninvasive positive pressure ventilation treatment for acute respiratory failure in SARS. Sleep Breath 2004; 8: 97-106.

64 Rana S, Jenad H, Gay PC, Buck CF, Hubmayr RD, Gajic O. Failure of non-invasive ventilation in patients with acute lung injury: observational cohort study. Crit Care 2006; 10: R79.

65 L'Her E, Deye N, Lellouche F, et al. Physiologic effects of noninvasive ventilation during acute lung injury. Am J Respir Crit Care Med 2005; 172: 1112-1118.

66 Agarwal R, Reddy C, Aggarwal AN, Gupta D. Is there a role for noninvasive ventilation in acute respiratory distress syndrome? A meta-analysis. Respir Med 2006; 100: 2235-2238.

67 Antonelli M, Conti G, Esquinas A, et al. A multiple-center survey on the use in clinical practice of noninvasive ventilation as a first-line intervention for acute respiratory distress syndrome. Crit Care Med 2007; 35: 18-25.

68 Rocker GM, Mackenzie MG, Williams B, Logan PM. Noninvasive positive pressure ventilation: successful outcome in patients with acute lung injury/ARDS. Chest 1999; 115: 173-177.

69 Jaber S, Delay JM, Chanques G, et al. Outcomes of patients with acute respiratory failure after abdominal surgery treated with noninvasive positive pressure ventilation. Chest 2005; 128: 2688-2695.

70 Squadrone V, Coha M, Cerutti E, et al. Continuous positive airway pressure for treatment of postoperative hypoxemia. JAMA 2005; 293: 589-595. 
71 Kindgen-Milles D, Muller E, Buhl R, et al. Nasal continuous positive airway pressure reduces pulmonary morbidity and length of stay following thoracoabdominal aortic surgery. Chest 2005; 128: 821-828.

72 Auriant I, Jallot A, Hervé P, et al. Noninvasive ventilation reduces mortality in acute respiratory failure following lung resection. Am J Respir Crit Care Med 2001; 164: 1231-1235.

73 Lumbierres M, Prats E, Farrero E, et al. Noninvasive positive pressure ventilation prevents postoperative pulmonary complications in chronic ventilators users. Respir Med 2007; 101: 62-68.

74 Antonelli M, Conti G, Bufi M, et al. Noninvasive ventilation for treatment of acute respiratory failure in patients undergoing solid organ transplantation: a randomized trial. JAMA 2000; 283: 235-241.

75 Depuydt PO, Benoit DD, Vandewoude KH, Decruyenaere JM, Colardyn FA. Outcome in noninvasively and invasively ventilated hematologic patients with acute respiratory failure. Chest 2004; 126: 1299-1306.

76 Hilbert G, Gruson D, Vargas F, et al. Noninvasive ventilation in immunosuppressed patients with pulmonary infiltrates, fever, and acute respiratory failure. $N$ Engl J Med 2001; 344: 481-487.

77 Confalonieri M, Calderini E, Terraciano S, et al. Noninvasive ventilation for treating acute respiratory failure in AIDS patients with Pneumocystis carinii pneumonia. Intensive Care Med 2002; 28: 1233-1238.

78 Nourdine K, Combes P, Carton MJ, Beuret P, Cannamela A, Ducreux JC. Does noninvasive ventilation reduce the ICU nosocomial infection risk? A prospective clinical survey. Intensive Care Med 1999; 25: 567-573.

79 Nava S, Ambrosino N, Clini E, et al. Noninvasive mechanical ventilation in the weaning of patients with respiratory failure due to chronic obstructive pulmonary disease. Ann Intern Med 1998; 128: 721-728.

80 Girault C, Daudenthun I, Chevron V, Tamion F, Leroy J, Bonmarchand G. Noninvasive ventilation as a systematic extubation and weaning technique in acute-on-chronic respiratory failure. Am J Respir Crit Care Med 1999; 160: 86-92.

81 Ferrer M, Esquinas A, Arancibia F, et al. Noninvasive ventilation during persistent weaning failure. A randomized controlled trial. Am J Respir Crit Care Med 2003; 168: 70-76.

82 Burns KE, Adhikari NK, Meade MO. A meta-analysis of noninvasive weaning to facilitate liberation from mechanical ventilation. Can J Anaesth 2006; 53: 305-315.

83 Vitacca M, Ambrosino N, Clini E, et al. Physiological response to pressure support ventilation delivered before and after extubation in COPD patients not capable of totally spontaneous autonomous breathing. Am J Respir Crit Care Med 2001; 164: 638-641.

84 Hilbert G, Gruson D, Portel L, Gbikpi-Benissan G, Cardinaud JP. Noninvasive pressure support ventilation in COPD patients with post-extubation hypercapnic respiratory insufficiency. Eur Respir J 1998; 11: 1349-1353.

85 Keenan SP, Powers C, McCormack DG, Block G. Noninvasive positive-pressure ventilation for postextubation respiratory distress: a randomized controlled trial. JAMA 2002; 287: 3238-3244.
86 Esteban A, Frutos-Vivar F, Ferguson ND, et al. Noninvasive positive-pressure ventilation for respiratory failure after extubation. N Engl J Med 2004; 350: 2452-2460.

87 Nava S, Gregoretti C, Fanfulla F, et al. Noninvasive ventilation to prevent respiratory failure after extubation in high-risk patients. Crit Care Med 2005; 33: 2465-2470.

88 Ferrer M, Valencia M, Nicolas JM, Bernadich O, Badia JR, Torres A. Early noninvasive ventilation averts extubation failure in patients at risk. A randomized trial. Am J Respir Crit Care Med 2006; 173: 164-170.

89 El Solh AA, Aquilina A, Pineda L, Dhanvantri V, Grant B, Bouquin P. Noninvasive ventilation for prevention of post-extubation respiratory failure in obese patients. Eur Respir J 2006; 28: 588-595.

90 Hess DR, Fessler HE. Should noninvasive positive pressure ventilation be used in all forms of acute respiratory failure? Respir Care 2007; 52: 568-578.

91 Clarke DE, Vaughan L, Raffin TA. Noninvasive positive pressure ventilation for patients with terminal respiratory failure: the ethical and economic costs of delaying the inevitable are too great. Am J Crit Care 1994; 1: 4-5.

92 Azoulay E, Alberti C, Bornstain C, et al. Improved survival in cancer patients requiring mechanical ventilatory support: impact of noninvasive mechanical ventilatory support. Crit Care Med 2001; 29: 519-525.

93 Levy M, Tanios MA, Nelson D, et al. Outcomes of patients with do-not-intubate orders treated with noninvasive ventilation. Crit Care Med 2004; 32: 2002-2007.

94 Schettino G, Altobelli N, Kacmarek RM. Noninvasive positive pressure ventilation reverses acute respiratory failure in selected "do-not-intubate" patients. Crit Care Med 2005; 33: 1976-1982.

95 Ambrosino N, Simonds A. The clinical management in extremely severe COPD. Respir Med 2007; 101: 1613-1624.

96 Nava S, Sturani C, Hartl S, et al. End-of-life decisionmaking in respiratory intermediate care units: a European survey. Eur Respir J 2007; 30: 1442-1450.

97 Chu C-M, Chan VL, Wong IWY, Leung W, Lin AWN, Cheung K-F. Noninvasive ventilation in patients with acute hypercapnic exacerbation of chronic obstructive pulmonary disease who refused endotracheal intubation. Crit Care Med 2004; 32: 372-377.

98 Cuomo A, Delmastro M, Ceriana P, et al. Noninvasive mechanical ventilation as a palliative treatment of acute respiratory failure in patients with end-stage solid cancer. Pall Med 2004; 18: 602-610.

99 Curtis JR, Cook DJ, Sinuff T, et al. Society of critical care medicine palliative noninvasive positive ventilation task force. Noninvasive positive pressure ventilation in critical and palliative care settings: understanding the goals of therapy. Crit Care Med 2007; 35: 932-939.

100 Fernandez R, Baigorri F, Artigas A. Noninvasive ventilation in patients with "do-not-intubate" orders: mediumterm efficacy depends critically on patient selection. Intensive Care Med 2007; 33: 350-354.

101 Antonelli M, Conti G, Riccioni L, Meduri GU. Noninvasive positive-pressure ventilation via face mask during bronchoscopy with BAL in high-risk hypoxemic patients. Chest 1996; 110: 724-728.

102 Maitre B, Jaber S, Maggiore SM, et al. Continuous positive airway pressure during fiberoptic bronchoscopy in 
hypoxemic patients. A randomized double-blind study using a new device. Am J Respir Crit Care Med 2000; 162: 1063-1067.

103 Antonelli M, Conti G, Rocco M, et al. Noninvasive positive-pressure ventilation versus conventional oxygen supplementation in hypoxemic patients undergoing diagnostic bronchoscopy. Chest 2002; 121: 1149-1154.

104 Da Conceicao M, Genco G, Favier JC, Bidallier I, Pitti R. Fiberoptic bronchoscopy during non-invasive positivepressure ventilation in patients with chronic obstructive lung disease with hypoxemia and hypercapnea. Ann Fr Anesth Reanim 2000; 19: 231-236.

105 Trachsel D, Erb TO, Frei FJ, Hammer J, on behalf of the Swiss Paediatric Respiratory Research Group. Use of continuous positive airway pressure during flexible bronchoscopy in young children. Eur Respir J 2005; 26: 773-777.

106 Elliott MW. Non-invasive ventilation for acute respiratory disease. Brit Med Bull 2004; 72: 83-97.

107 Kelly BJ, Matthay MA. Prevalence and severity of neurologic dysfunction in critically ill patients. Influence on need for continued mechanical ventilation. Chest 1993; 104: 1818-1824.

108 Ambrosino N, Foglio K, Rubini F, Clini E, Nava S, Vitacca M. Non-invasive mechanical ventilation in acute respiratory failure due to chronic obstructive pulmonary disease: correlates for success. Thorax 1995; 50: 755-757.

109 Confalonieri M, Garuti G, Cattaruzza MS, et al. A chart of failure risk for noninvasive ventilation in patients with COPD exacerbation. Eur Respir J 2005; 25: 348-355.

110 Nava S, Ceriana P. Causes of failure of non-invasive mechanical ventilation. Respir Care 2004; 49: 295-303.

111 Ferrer M, Ioanas M, Arancibia F, Marco MA, de la Bellacasa JP, Torres A. Microbial airway colonization is associated with noninvasive ventilation failure in exacerbation of chronic obstructive pulmonary disease. Crit Care Med 2005; 33: 2003-2009.

112 Moretti M, Cilione C, Tampieri A, Fracchia C, Marchioni A, Nava $S$. Incidence and causes of non-invasive mechanical ventilation failure after initial success. Thorax 2000; 55: 819-825.

113 Carlucci A, Delmastro M, Rubini F, Fracchia C, Nava S. Changes in the practice of non-invasive ventilation in treating COPD patients over 8 years. Intensive Care Med 2003; 29: 519-525.

114 Girou E, Brun-Buisson C, Taillé S, Lemaire F, Brochard L. Secular trends in nosocomial infections and mortality associated with noninvasive ventilation in patients with exacerbation of COPD and pulmonary edema. JAMA 2003; 290: 2985-2991.

115 Chevrolet JC, Jolliet P, Abajo B, Toussi A, Louis M. Nasal positive pressure ventilation in patients with acute respiratory failure. Difficult and time-consuming procedure for nurses. Chest 1991; 100: 775-782.

116 Ambrosino N, Corrado A. Obstructive pulmonary disease with acute respiratory failure. In: Muir J-F, Simonds AK, Ambrosino N, eds. Noninvasive Mechanical Ventilation. Eur Respir Mon 2001; 16: 11-32.

117 Corrado A, Roussos C, Ambrosino N, et al. Respiratory intermediate care units: a European survey. European Respiratory Society Task Force on epidemiology of respiratory intermediate care in Europe. Eur Resp 2002; 20: 1343-1350.

118 Maheshwari V, Paioli D, Rothaar R, Hill NS. Utilization of noninvasive ventilation in acute care hospitals: a regional survey. Chest 2006; 129: 1226-1233.

119 Burns KEA, Sinuff T, Adhikari NKJ, et al. Bilevel noninvasive positive pressure ventilation for acute respiratory failure: Survey of Ontario practice. Crit Care Med 2005; 33: 1477-1483.

120 Crummy F, Buchan C, Miller B, Toghill J, Naughton MT. The use of noninvasive mechanical ventilation in COPD with severe hypercapnic acidosis. Respir Med 2007; 101: 53-61.

121 Kwok H, McCormack J, Cece R, Houtchens J, Hill NS. Controlled trial of oronasal versus nasal mask ventilation in the treatment of acute respiratory failure. Crit Care Med 2003; 31: 468-473.

122 Costa R, Navalesi P, Antonelli M, et al. Physiologic evaluation of different levels of assistance during noninvasive ventilation delivered through a helmet. Chest 2005; 128: 2984-2990.

123 Racca F, Appendini L, Gregoretti C, et al. Effectiveness of mask and helmet interfaces to deliver noninvasive ventilation in a human model of resistive breathing. $J$ Appl Physiol 2005; 99: 1262-1271.

124 Moerer O, Fischer S, Hartelt M, Kuvaki B, Quintel M, Neumann P. Influence of two different interfaces for noninvasive ventilation compared to invasive ventilation on the mechanical properties and performance of a respiratory system. Chest 2006; 129: 1424-1431.

125 Navalesi P, Costa R, Ceriana P, et al. Non-invasive ventilation in chronic obstructive pulmonary disease patients: helmet versus facial mask. Intensive Care Med 2007; 33: 74-81.

126 Patroniti N, Saini M, Zanella A, Isgrò S, Pesenti A. Danger of helmet continuous positive airway pressure during failure of fresh gas source supply. Intensive Care Med 2007; 33: 153-157.

127 Hui DS, Hall SD, Chan MTV. Noninvasive positivepressure ventilation. An experimental model to assess air and particle dispersion. Chest 2006; 130: 730-740.

128 Lellouche F, Maggiore SM, Deye N, et al. Effect of the humidification device on the work of breathing during noninvasive ventilation. Intensive Care Med 2002; 28: 1582-1589.

129 Vitacca M, Rubini F, Foglio K, Scalvini S, Nava S, Ambrosino N. Non-invasive modalities of positive pressure ventilation improve the outcome of acute exacerbations in COLD patients. Intensive Care Med 1993; 19: 450-455.

130 Vitacca M, Clini E, Pagani M, Bianchi L, Rossi A, Ambrosino N. Physiologic effects of early administered mask PAV (proportional assist ventilation) in patients with chronic obstructive pulmonary disease and acute respiratory failure. Crit Care Med 2000; 28: 1791-1796.

131 Gay PC, Hess DR, Hill NS. Noninvasive proportional assist ventilation for acute respiratory insufficiency. A comparison with pressure support ventilation. Am J Respir Crit Care Med 2001; 164: 1606-1611. 
132 Ambrosino N, Rossi A. Proportional assist ventilation (PAV): a significant advance or a futile struggle between logic and practice? Thorax 2002; 57: 272-276.

133 Vitacca M, Nava S, Confalonieri M, et al. The appropriate setting of noninvasive pressure support ventilation in stable COPD patients. Chest 2000; 118: 1286-1293.

134 Prinianakis G, Delmastro M, Carlucci A, Ceriana P, Nava S. Effect of varying the pressurisation rate during noninvasive pressure support ventilation. Eur Respir J 2004; 23: 314-320.

135 Richard JC, Carlucci A, Breton L, et al. Bench testing of pressure support ventilation with three different generations of ventilators. Intensive Care Med 2002; 28: 1049-1057.

136 Tassaux D, Strasser S, Fonseca S, Dalmas E, Jolliet P. Comparative bench study of triggering, pressurisation, and cycling between the home ventilator VPAP II and three ICU ventilators. Intensive Care Med 2002; 28: 1254-1261.

137 Miyoshi E, Fujino Y, Uchiyama A, Mashimo T, Nishimura M. Effects of gas leak on triggering function, humidification, and inspiratory oxygen fraction during noninvasive positive airway pressure ventilation. Chest 2005; 128: 3691-3698.

138 Mulqueeny Q, Ceriana P, Carlucci A, Fanfulla F, Delmastro M, Nava S. Automatic detection of ineffective triggering and double triggering during mechanical ventilation. Intensive Care Med 2007; 33: 2014-2018.

139 Fanfulla F, Taurino AE, Lupo ND, Trentin R, D'Ambrosio C, Nava S. Effect of sleep on patient/ventilator asynchrony in patients undergoing chronic non-invasive mechanical ventilation. Respir Med 2007; 101: 1702-1707.

140 Vignaux L, Tassaux D, Jolliet P. Performance of noninvasive ventilation modes on ICU ventilators during pressure support: a bench model study. Intensive Care Med 2007; 33: 1444-1451.

141 Tuggey JM, Delmastro M, Elliott MW. The effect of mouth leak and humidification during nasal non-invasive ventilation. Respir Med 2007; 101: 1874-1879.

142 Jaber S, Chanques G, Matecki S, et al. Comparison of the effects of heat and moisture exchangers and heated humidifiers on ventilation and gas exchange during noninvasive ventilation. Intensive Care Med 2002; 28: 1590-1594.

143 Plant PK, Owen JL, Elliott MW. Non-invasive ventilation in acute exacerbations of chronic obstructive pulmonary disease: long term survival and predictors of in-hospital outcome. Thorax 2001; 56: 708-712.

144 Keenan SP, Gregor J, Sibbald WJ, Cook D, Gafni A. Noninvasive positive pressure ventilation in the setting of severe, acute exacerbation of chronic obstructive pulmonary disease: more effective and less expensive. Crit Care Med 2000; 28: 2094-2102.

145 Plant PK, Owen JL, Parrott S, Elliott MW. Cost effectiveness of ward based non-invasive ventilation for acute exacerbations of chronic obstructive pulmonary disease: economic analysis of randomized controlled trial. BMJ 2003; 326: 956-961.

146 Bertolini G, Confalonieri M, Rossi C, et al. Costs of COPD. Differences between intensive care unit and respiratory intermediate intensive care unit. Respir Med 2005; 99 894-900.

147 Jaber S, Fodil R, Carlucci A, et al. Noninvasive ventilation with helium-oxygen in acute exacerbations of chronic obstructive pulmonary disease. Am J Respir Crit Care Med 2000; 161: 1191-1200.

148 Jolliet P, Tassaux D, Roeseler J, et al. Helium-oxygen versus air-oxygen noninvasive pressure support in decompensated chronic obstructive diseases: A prospective multicenter study. Crit Care Med 2003; 31: 878-884.

149 Gainnier M, Forel JM. Clinical review: use of heliumoxygen in critically ill patients. Crit Care 2006; 10: 241.

150 Tassaux D, Gainnier M, Battisti A, Jolliet P. Heliumoxygen decreases inspiratory effort and work of breathing during pressure support in intubated patients with chronic obstructive pulmonary disease. Intensive Care Med 2005; 31: 1501-1507.

151 Hess DR. Heliox and noninvasive positive-pressure ventilation: a role for heliox in exacerbations of chronic obstructive pulmonary disease? Respir Care 2006; 51: 640-650.

152 Devlin JW, Nava S, Fong JJ, Imad B, Hill NS. Survey of sedation practices during noninvasive positive-pressure ventilation to treat acute respiratory failure. Crit Care Med 2007; 35: 2298-2302.

153 Constantin JM, Schneider E, Cayot-Constantin S, et al. Remifentanil-based sedation to treat noninvasive ventilation failure: a preliminary study. Intensive Care Med 2007; 33: 82-87. 